\title{
Successful intubation with Macintosh laryngoscope after failed intubation with McGrath video laryngoscope in post burn contracture of the neck
}

\author{
R Salhotra ${ }^{I^{*}}$, V Arora $^{2}$, CS Sharma ${ }^{3}$, AK Sethi $^{4}$ \\ Assistant Professor ${ }^{1}$, Postgraduate student ${ }^{2}$ Specialist ${ }^{3}$, Director Professor and Head ${ }^{4}$, Department of \\ Anaesthesiology and Critical Care, University College of Medical Sciences and Guru Teg Bahadur Hospital, \\ Delhi, India.
}

*Corresponding author: rashmichabra@yahoo.com

\begin{abstract}
A 29 year old woman, a case of post burn contracture of the neck came for the release. McGrath video laryngoscope was chosen as the initial tool for airway management. Despite an excellent view, intubation failed due to lack of working airway space available after use of video laryngoscope. Successful intubation was achieved with Macintosh laryngoscope although the laryngoscopy view was Cormack and Lehane grade IIIa and percentage of glottic opening score was $25 \%$. More research into the predictors of difficult laryngoscopy or intubation with the video laryngoscope needs to be done before recommending these devices for use in difficult airway scenarios.
\end{abstract}

Keywords: difficult airway; video laryngoscope; post burn contracture; failed intubation.

\section{Introduction}

Video laryngoscopes (VLS) are newer equipments that are gaining popularity for use in difficult airway (DA) management. They are being used in simulated difficult airway scenarios and in patients with immobilised necks. Recently there has been a suggestion to include VLS in the anticipated DA algorithms. ${ }^{1}$ They provide a look "around the corner" and are proving to be good educational tools. The excellent views have not always been translated into successful intubations. ${ }^{2}$

\section{Case History}

A 29 year old woman came for post burn neck contracture release. Airway examination revealed two finger breadth mouth opening (Figure 1), buck teeth, Mallampati Class III, limited neck extension (Figure 2) and thyromental distance of $5 \mathrm{~cm}$ with perioral scarring. Systemic examination was normal. The patient was explained about anticipated difficult airway, but she was non-consenting for awake fiberoptic intubation. Tracheostomy consent was obtained pre-operatively. DA cart was checked and surgical team was ready for performing an emergency tracheostomy if required. Premedication was done with glycopyrrolate $0.2 \mathrm{mg}$ i.v.

In the operation theatre, appropriate monitors were attached and venous access was secured. After preoxygenation, anaesthesia was induced with fentanyl $75 \mathrm{mcg}$ i.v. and propofol $100 \mathrm{mg}$ i.v. Bag and mask ventilation was performed with $33 \% \mathrm{~N}_{2} \mathrm{O}$ in $\mathrm{O}_{2}$ and sevoflurane. After achieving adequate depth of anaesthesia, laryngoscopy was attempted with $\mathrm{McGrath}^{\circledR}$ video laryngoscope (Aircraft Medical, Edinburgh,UK) (MVL).Cormack and Lehane (C\& L)

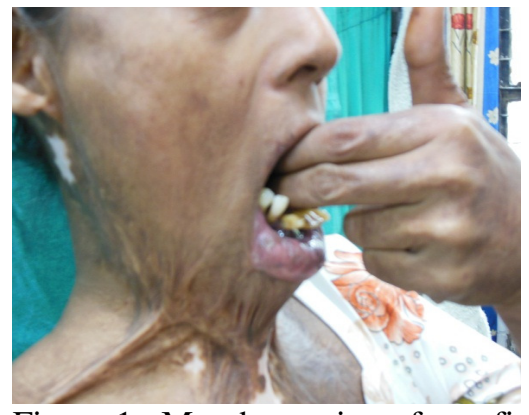

Figure 1: Mouth opening of two finger breadth

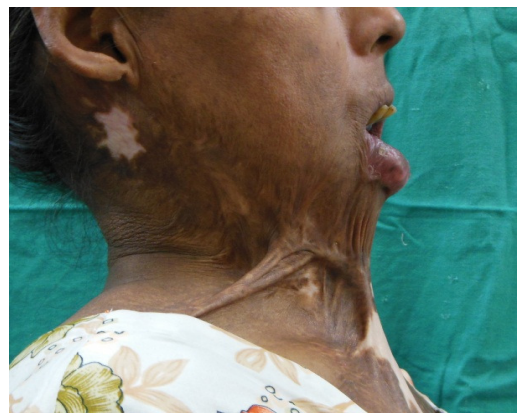

Figure 2: limited neck extension and reduced thyromental distance

grade I and percentage of glottis opening (POGO) score of $100 \%$ was found. Intubation was attempted with a $7.5 \mathrm{~mm}$ I.D. endotracheal tube (ETT). But ETT could not be introduced into oral cavity as tongue was obstructing the passage. A second attempt was made to improve laryngoscopy but ETT still could not be introduced and there was trauma to the tonsillar pillar by the laryngoscope blade and the bleeding obscured the view. 
A third attempt at laryngoscopy was done with a Macintosh laryngoscope (ML). The modified C\&L grade was IIIa and POGO score was $25 \%$. Intubation was possible with a styletted ETT as tongue could be displaced with the ML blade.

\section{Discussion}

A wide variety and different designs of VLS are available in the market. Researchers have found that VLS have potential roles in DA..$^{3-5}$ These devices are now being recommended for use in anticipated DA scenarios. ${ }^{6,7}$ VLS have proven effective in providing good views at laryngoscopy as they do not require alignment of oropharyngeal-laryngeal axes. ${ }^{4}$

MVL is one such VLS and was chosen as the initial laryngoscope to facilitate intubation in this patient. Back-up plan included the conventional approach to anticipated DA.

Difficult or failed intubation with MVL has previously been reported despite good glottic views. ${ }^{2,8,9}$ The reasons quoted are lack of expertise ${ }^{2}$, blurring of vision due to fogging, secretions, blood or vomitus and requirement of acute angulation of ETT to enter the larynx. ${ }^{4} \mathrm{MVL}$ also has a CameraStick ${ }^{\mathrm{TM}}$ which reduces the space for the tongue to be accommodated and deflected away. So there is less space available for introduction of ETT inside the oral cavity.

In the first laryngoscopy attempt, there was difficulty in introducing ETT into the mouth due to limited space. Previously, it has been noted with GlideScope ${ }^{\circledR}$ that difficult intubation may be because of limited oropharyngeal space. The difficulty increases when there is limited neck mobility. ${ }^{1}$ The same was the reason in this case where there was perioral scarring along with limited neck mobility.

The anaesthesiologist performing the intubation had done more than fifty successful intubations with the device, hence lack of expertise was ruled out. In the second attempt, trauma to tonsillar pillar occurred because more force was applied to displace the tongue to the left side leading to bleeding which obscured the view. Even though VLS provided excellent view, intubation failed.

In the third attempt with ML, C\&L grade was IIIa with POGO of $25 \%$, but intubation could be performed successfully. ML is designed to provide enough space to accommodate the tongue and displace it to left, providing room for ETT introduction. Hence no difficulty was encountered during intubation despite poor glottis view.

\section{Conclusion}

VLS still have a long way to go before they can be included in DA algorithms. Better designs of VLS with sleeker camera cords or sticks to provide enough room for tongue displacement need to be developed. Additional indices or tests for detecting difficulty in laryngoscopy or intubation with VLS need to be developed.

\section{References}

1. Saxena S. The ASA difficult airway algorithm: is it time to include video laryngoscopy and discourage blind and multiple intubation attempts in the nonemergency pathway? Anesth Analg 2009; 108: 1052 .

http://dx.doi.org/10.1213/ane.0b013e31819341e4 PMid: 19224832

2. Sharma DJ, Weightman WM, Travis A. Comparison of the Pentax Airway Scope and McGrath Video laryngoscope with the Macintosh laryngoscope in tracheal intubation by anaesthetists unfamiliar with video laryngoscopes: a manikin study. Anaesth Intensive Care 2010; 38:39-42. PMid:20191775

3. Su YC, Chen CC, Lee YK, Lin KJ. Comparison of video laryngoscopes with direct laryngoscopy for tracheal intubation: a meta-analysis of randomised trials. Eur $J$ Anaesthesiol 2011;28:788-95.

http://dx.doi.org/10.1097/EJA.0b013e32834a34f3 PMid:21897263

4. Noppens RR, Möbus S, Heid F, Schmidtmann I, Werner C, Piepho T. Evaluation of the McGrath series 5 video laryngoscoe after failed direct laryngoscopy. Anaesthesia 2010;65:716-20. http://dx.doi.org/10.1111/j.1365-2044.2010.06388.x PMid:20528841

5. Shippey B, Ray D, McKeown D. Use of the McGrath video laryngoscope in the management of difficult and failed tracheal intubation. $\mathrm{Br} J$ Anaesth.2008;100:116-9. http://dx.doi.org/10.1093/bja/aem303 PMid: 17959584

6. Aziz MF, Dillman D, Fu R, Brambrink AM. Comparative effectiveness of the C-MAC video laryngoscope versus direct laryngoscopy in the setting of the predicted difficult airway. Anesthesiology.2012;116:629-36.

http://dx.doi.org/10.1097/ALN.0b013e318246ea34 PMid:22261795

7. Serocki G, Bein B, Scholz J, Dörges V. Management of the predicted difficult airway: a comparison of conventional blade laryngoscopy with video-assisted blade laryngoscopy and the GlideScope. Eur J Anaesthesiol 2010;27:24-30. http://dx.doi.org/10.1097/EJA.0b013e32832d328d PMid:19809328

8. Shippey B, Ray D, McKeown D. Case series: the McGrath video laryngoscope - an initial clinical evaluation. Can J Anesth 2007;54:307-13. http://dx.doi.org/10.1007/BF03022777 PMid: 17400984 
9. Niforopoulou P, Pantazapoulos I, Demestiha T, Koudouna E, Xanthos T. Video-laryngoscopes in the adult airway management: a topical review of literature. Acta Anaesthesiol Scand 2010;54:1050-

61.

http://dx.doi.org/10.1111/j.1399-6576.2010.02285.x PMid:20887406

10. Thompson C, Moga R, Crosby ET. Failed video laryngoscope intubation in a patient with diffuse idiopathic skeletal hyperostosis and spinal cord injury. Can J Anesth 2010;57:679-82. http://dx.doi.org/10.1007/s12630-010-9313-5

PMid:20428989 